\title{
A VISIT TO AN OPHTHALMIC CLINIC IN VIENNA
}

B Y

S. M. TYRRELL

LONDON

THE first impression that one has in the Viennese clinics is the extraordinarily warm welcome that is extended by all the staff to foreign visitors. The professors welcomed one with open arms, and asked after old English acquaintances.

I visited the clinic of Professor Meller, where I was received bo Dr. Joseph Urbanek, the Assistant Professor, who spent the firs morning introducing me to his Tuberculin injection clinic. We were shown 187 patients, suffering from various diseases of the lidit conjunctiva, cornea, and uveal tract, all of whom received 1c.c. of Tebeprotein, which Dr. Urbanek uses almost exclusively. Most of these diseases were those which in this country we are inclined to attribute to a hidden septic focus such as the teeth; and it was interesting to hear that Dr. Urbanek thinks that the teeth have nothing to do with these eye conditions; while we were verd interested to note that at any rate 80 out of the last 135 patiegefts who attended on that morning had one or more gold-crowned teetth in their mouths.

The other point that impressed was that the cases of phlyctenulat keratitis and conjunctivitis were nearly all adults. Only 3 childrets were seen out of about 35 in all. On the other hand we were show $\mathrm{X}$-rays of the chest of all these children, and all had areas of diseasef apparently active, at one or other apex.

The next morning we saw Professor Meller operate on three cataracts. He operates from the patient's right, in the usual continental manner, and performs a combined extraction. In one case of secondary cataract, he performed a division of the posterior synechiae with two blunt-pointed knives with edges on opposite side of the blade, one for each side of the pupil. He then performed å intracapsular extraction of the lens, which left a good clear pupi $\mathrm{He}$ only performs intracapsular extractions in these cases. The younger surgeons perform them in every case now.

In acute glaucoma a Graefe iridectomy is done, though no attem is made to secure a broad iridectomy, as is usually done here, bo cause Meller claims that the results are better with the narrow but complete iridectomy, and says that the broad one in his hands more liable to lead to damage to the lens. In chronic glaucoma ad iridodialysis alone is performed. Meller detests trephine and iridencleisis more than any other operations in the calendar. 
The most interesting demonstration I witnessed was a "parade" of Dr. Urbanek's last 70 detachment cases, with an 80 per cent. immediate cure rate and a 60 per cent. one year cure rate. This is higher than most ftgures obtained in this country, and is certainly not a fiction, as I examined all the cases myself, good and bad results. Dr. Urbanek uses the electrolysis method, with direct current, using the cathode and watching by direct ophthalmoscopy for the plume of gas bubbles to see if he is near the hole. He claims that this method obviates the necessity of localising the hole so accurately, and also reduces the amount of burning round an area of electrolysis. This gives a prettier fundus picture after, as well as giving better adhesion of the retina.

It is important to pierce all the coats of the eye with the needle and to see the needle in the eye by direct ophthalmoscopy. If Dr. Urbanek is not satisfied with the degree of burning obtained by electrolysis, he also covers the area lightly with the Larsen ball electrode, using diathermy coagulating current. This had been done in about half the cases shown, but one would imagine that as the surgeon grew more familiar with the method there would be less need for this. One waits for twenty minutes or so after the electrolysis has been completed to allow the sub-retinal fluid to escape and to allow the retina to settle back and then re-examines the retina to see whether the degree of burning is satisfactory or not.

Among these cases were two who had had detached retinae for. four years, and both had now been cured, one with 6/18 for 9 months, the other with $6 / 24$ for 12 months.

Their other technique is similar to ours as far as operations are concerned, but they have many unusual and apparently not very successful treatments for what we consider the hopeless eye diseases. I saw a clinic of about a dozen cases of retinitis pigmentosa, which were being treated by massive doses of ovarian hormone. It was said that the males did better than the females on this treatment, but one felt that the truth was that no impression was made on either sex, at any rate the fields showed no improvement, and the patients themselves grumbled just as much as ours do.

The wards of the eye clinics are housed in the old hospital founded by the Emperor Joseph II in 1874, and consequently have not the airiness nor the bed space of our eye hospitals, but they manage to carry out their treatment very well all the same. The operating theatre is likewise housed in a makeshift room, and is not so up-todate as ours, but the lighting is good, and makes up to some extent for the other deficiencies. The theatre porter, an old patient, with one eye, is trained to prepare the eye for operation, and to assist at the operation; at the end he helps the patient carefully to his feet and escorts him back to bed.

To conclude, the most important thing to be learnt is, in the words 
of Professor Meller, "There is no one way of treatment in medicin that is the best. It is for each to select the particular line of treatment that seems best to him and perfect himself in it, and he wi then get as good results with that method as somebody else elsewhere is getting with his particular method."

\section{CORRECTION OF PTOSIS BY TWO STRIPS OF FASCIA LATA}

\section{BY}

\section{J. A. Magnus}

BIRMINGHAM

MANY operations have been designed for the correction of ptosit: To instance a few, there are Everbusch's operation, in which the levator palpebrae muscle is advanced; Hess's operation in which three sutures are employed; Motais' operation in which a narrow tongue of the superior rectus is attached to the upper border of the tarsus, and Derby's operation in which a hammock of the fasc lata is used to pull the upper lid upwards.

The great disadvantage common to all is the more or less tot lagophthalmos with which the operator has to deal at the ends. of the operation, and therefore the necessity of protecting the corpiea from ulceration. This, however, is avoided by the method describes by Lexer of Munich in 1923.

Lexer employs two strips of fascia lata to pull the lid up in manner similar to that in which Hess uses his sutures. The advantage of Lexer's technique is that a direct connection is made between the frontalis muscle and the lid margin by a tissue which can be left in place. This, in due course, will undergo a naturat contraction and so emphasize the effect of the operation. Sine्ष this method is apparently not well known in this country, and sincie I have had some experience in this operation on the Continent well as in England, it may be of service to outline briefly the main points :

I. Preparation: The day before the operation the eyebrow shaved and its position delineated with silver nitrate stick. The skin of the thigh and face is prepared as for any other operation.

II. Operation :

(1) Two per cent. novocaine with adrenalin is used for locor injection. The thigh below the great trochanter is incised for distance of about $8 \mathrm{cms}$. and the fascia lata exposed. Two paraller incisions $2.5 \mathrm{cms}$. long are made in the fascia $6-8 \mathrm{mms}$. apart. The portion of the fascia is separated and transferred to a basin of 